\title{
Factors influencing outcomes of the treatment of positional plagiocephaly in infants: a 7-year experience
}

\author{
Sandi Lam, MD, MBA, ${ }^{1}$ I-Wen Pan, PhD, ${ }^{1}$ Ben A. Strickland, MD,, Caroline Hadley, MD, ${ }^{1}$ \\ Bradley Daniels, BS, ${ }^{1}$ Jim Brookshier, CPO, LPO, ${ }^{2}$ and Thomas G. Luerssen, MD' \\ 1Department of Neurosurgery/Division of Pediatric Neurosurgery, Texas Children's Hospital/Baylor College of Medicine; and \\ ${ }^{2}$ Hanger Clinic, Houston, Texas
}

OBJECTIVE Following institution of the Back to Sleep Campaign, the incidence of sudden infant death syndrome decreased while the prevalence of positional skull deformation increased dramatically. The management of positional deformity is controversial, and treatment recommendations and outcomes reporting are variable. The authors reviewed their institutional experience (2008-2014) with the treatment of positional plagiocephaly to explore factors associated with measured improvement.

METHODS A retrospective chart review was conducted with risk factors and treatment for positional head shape deformity recorded. Univariate and multivariate analyses were used to assess the impact of these variables on the change in measured oblique diagonal difference (ODD) on head shape surface scanning pre- and posttreatment.

RESULTS A total of 991 infants aged less than 1 year were evaluated for cranial positional deformity in a dedicated clinical program. The most common deformity was occipital plagiocephaly $(69.5 \%)$, followed by occipital brachycephaly $(18.4 \%)$ or a combination of both deformities (12.1\%). Recommended treatment included repositioning (RP), physical therapy (PT) if indicated, or orthotic treatment with a customized cranial orthosis (CO) according to an age- and risk factor-dependent algorithm that the authors developed for this clinic. Of the 991 eligible patients, 884 returned for at least 1 follow-up appointment. A total of 552 patients were followed to completion of their treatment and had a full set of records for analysis: these patients had pre- and posttreatment 2D surface scanner evaluations. The average presenting age was 6.2 months (corrected for prematurity for treatment considerations). Of the 991 patients, $543(54.8 \%)$ had RP or PT as first recommended treatment. Of these 543 patients, $137(25.2 \%)$ transitioned to helmet therapy after the condition did not improve over 4-8 weeks. In the remaining cases, RP/PT had already failed before the patients were seen in this program, and the starting treatment recommendation was $\mathrm{CO}$. At the end of treatment, the measured improvements in ODD were $36.7 \%, 33.5 \%$, and $15.1 \%$ for patients receiving CO, RP/PT/CO, and RP/PT, respectively. Univariate analysis showed that sex, race, insurance, diagnosis, sleep position preference, torticollis history, and multiple gestation were not significantly associated with magnitude of ODD change during treatment. On multivariate analysis, corrected age at presentation and type of treatment received were significantly associated with magnitude of ODD change. Orthotic treatment corresponded with the largest ODD change, while the RP/PT group had the least change in ODD. Earlier age at presentation corresponded with larger ODD change.

CONCLUSIONS Earlier age at presentation and type of treatment impact the degree of measured deformational head shape correction in positional plagiocephaly. This retrospective study suggests that treatment with a custom $\mathrm{CO}$ can result in more improvement in objective measurements of head shape.

https://thejns.org/doi/abs/10.3171/2016.9.PEDS16275

KEY WORDS plagiocephaly; positional skull deformity; brachycephaly; cranial; infant; craniofacial

ABBREVIATIONS $\mathrm{CO}$ = cranial orthosis; $\mathrm{ODD}=$ oblique diagonal difference; $\mathrm{OR}=$ odds ratio; $\mathrm{PT}$ = physical therapy; $\mathrm{RP}=$ repositioning; $\mathrm{SD}=$ standard deviation; $\mathrm{SIDS}=$ sudden infant death syndrome.

SUBMITTED May 19, 2016. ACCEPTED September 12, 2016

INCLUDE WHEN CITING Published online January 13, 2017; DOI: 10.3171/2016.9.PEDS16275. 
$\mathrm{I}$ N 1992 the American Academy of Pediatrics published recommendations that infants sleep in the supine position to decrease the incidence of sudden infant death syndrome (SIDS). While this has been successful in reducing SIDS, it has also resulted in a substantial increase in the prevalence of positional skull deformity. ${ }^{15}$ Positional plagiocephaly and brachycephaly typically are noted at 2-4 months of age and have decreasing prevalence as children grow older. This deformity is most frequently associated with torticollis and thought to be possibly secondary to motor delay, ${ }^{4,6,16}$

The common positional skull deformation patterns are unilateral occipital flattening of the skull (occipital plagiocephaly) and symmetrical occipital flattening (occipital brachycephaly). Plagiocephaly can have compensatory ipsilateral frontal bossing of the forehead and anterior shift of the ipsilateral ear.,13 Brachycephaly can have compensatory biparietal bossing and occipital lift. ${ }^{1}$

The first-line treatment is conservative, ${ }^{9}$ utilizing repositioning (RP) maneuvers to alleviate persistent external forces on the affected area, along with physical therapy (PT) to treat torticollis, if present. If there is persistent deformity despite RP, PT, and increasing mobility, cranial orthosis (CO) treatment (also known as helmet therapy) has been recommended..$^{10}$ While a variety of devices have been marketed for this application, all have the same basic structure, which is a custom-fit rigid outer shell with an inner foam lining. While exactly how CO treatment improves skull shape is unclear, it is thought that the orthosis redistributes external pressure and also takes advantage of the rapid rate of brain growth in normal infants by leaving room for preferential directed growth on the side of the deformity. Wearing the $\mathrm{CO}$ for 23 hours a day is generally recommended..$^{12,18}$ Different treatment algorithms have been reported, though very few have been used in direct comparison.

We report our 7-year institutional experience (20072014) in the treatment of positional skull deformation at Texas Children's Hospital. Our purpose was 2-fold: to identify relevant factors used to guide treatment recommendations for positional skull deformity and to evaluate the effectiveness of the received treatment using comparisons of pretreatment and posttreatment 2D surface scans. We also describe our treatment algorithm.

\section{Methods}

In 2007, the senior author (T.G.L.) established a dedicated clinic for the assessment and treatment of cranial deformity in infants. All healthy infants under the age of 1 year who entered a treatment program for positional cranial deformation (occipital plagiocephaly, occipital brachycephaly, or both) were included in this study. Patients with craniosynostosis, ventriculoperitoneal shunts, severe medical/developmental issues, cephalohematomas, and complex cranial deformities unrelated to positional mechanisms were excluded from the study. Patients who received any orthotic treatment prior to presentation in our clinic were also excluded.

\section{Evaluation}

A detailed history was obtained from all patients' fami-

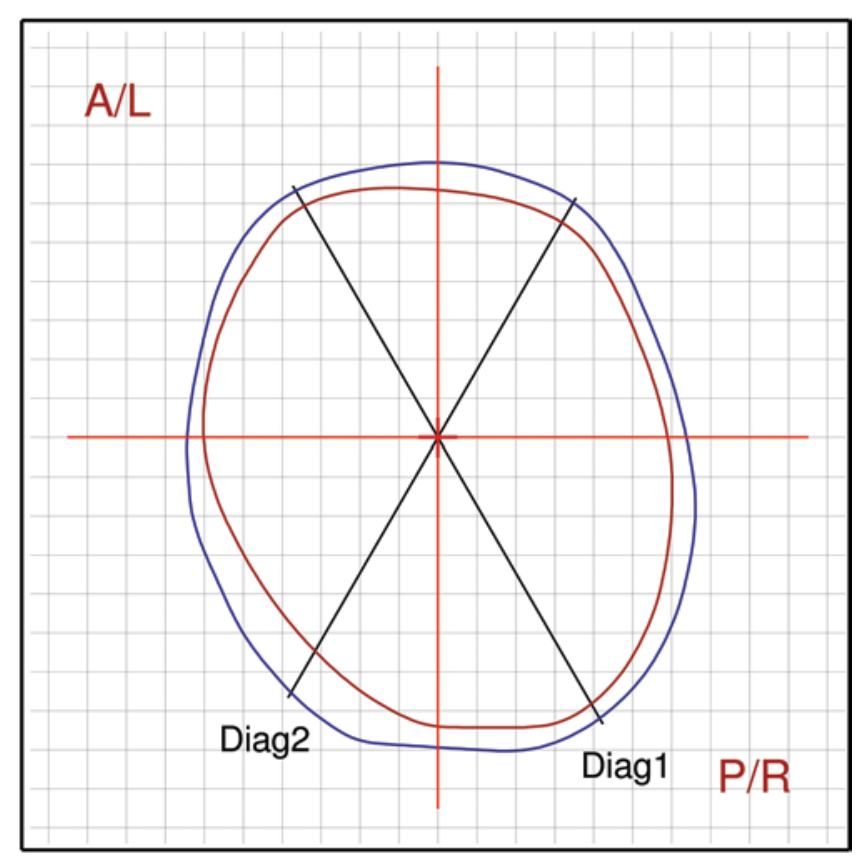

FIG. 1. Laser surface STAR scan. This patient presented with severe left occipital positional plagiocephaly at 3 months of age, with an ODD of $20.6 \mathrm{~mm}$ (red/inner outline, initial scan). The infant was treated with RP and PT and monitored at 1.5-month intervals. After 3 months of conservative RP and PT, the ODD had decreased considerably to 11.2 (blue/ outer outline, follow-up scan). The patient continued with this course of conservative management. $A=$ anterior; Diag = diagonal; $L=$ left; $P=$ posterior; $\mathrm{R}=$ right. Figure is available in color online only.

lies, looking for characteristic symptoms related to cranial deformity, including prenatal constraint symptoms, preferential sleeping positions, use of swaddling, and positioning strategies. All patients were screened for restricted neck movement indicative of torticollis. All patients underwent cranial measurement with a STARscanner (Orthomerica Products Inc.) 3D laser surface scan at presentation and at each follow-up appointment. All scans were performed by a single orthotist (J.B.) with extensive experience using the device. All follow-up studies were performed with the same instrument. Analysis of the data were automated, with output generated via proprietary software from Orthomerica. Level 3 was the slice used for treatment decisions and as the standard measurement for comparison in all patients. This section at Level 3 is defined as onethird of the distance between the base plane and the vertex. The oblique diagonal difference (ODD) and cephalic ratio were recorded. Figure 1 shows an example STAR scan with described measurements. The cephalic ratio is calculated from cranial width divided by cranial anteriorposterior length.

Measurements obtained at the initial visit and the last visit were used for the outcome comparisons. Outcomes of interest were surface laser scan measurements with expected improvement in asymmetry of ODD in plagiocephaly to less than $10 \mathrm{~mm}$ of difference or in normalization of cephalic ratio in brachycephaly to less than 0.94 .

Measurements on laser surface scans were used for 


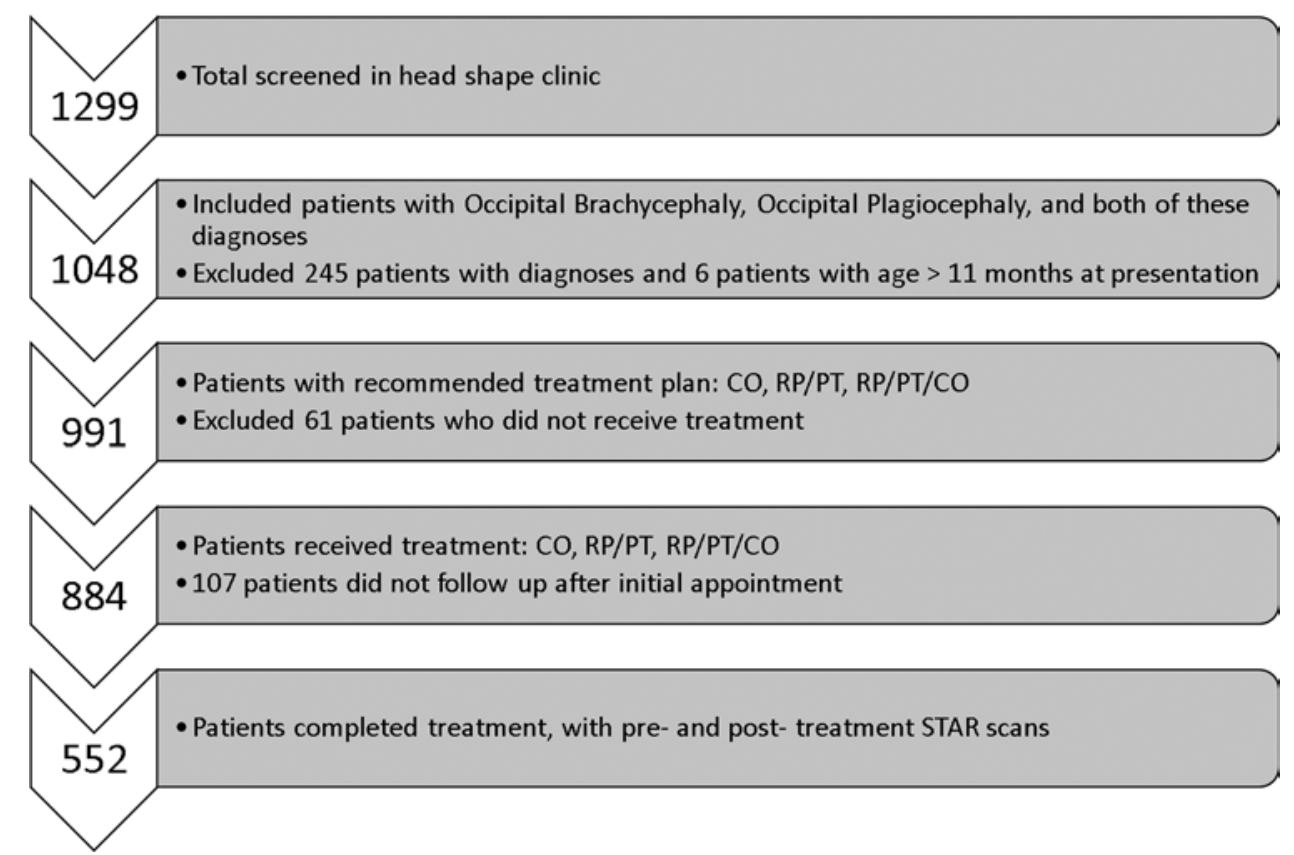

FIG. 2. Study cohort.

definitions in this study: for positional plagiocephaly, an ODD less than $10 \mathrm{~mm}$ was considered mild, $10-15 \mathrm{~mm}$ moderate, and greater than $15 \mathrm{~mm}$ severe. For positional occipital brachycephaly, a cephalic ratio less than 0.95 was considered mild, 0.95-1.0 moderate, and greater than 1.0 severe. Dual diagnosis of plagiocephaly and brachycephaly was defined by measurements in this study for objective measures, though in clinical practice, measurements do not necessarily supersede clinical judgement in clinical practice.

\section{Treatment Algorithm and Rationale}

Patients presenting at the younger end of the age spectrum (1-4 months chronological age, adjusted for prematurity) with ODD greater than $10 \mathrm{~mm}$ or cephalic ratio greater than 0.95 are recommended RP as first-line management and PT if torticollis is present. Patients are reexamined and re-scanned every 4-6 weeks.

If the head shape deformity does not improve (or if it progresses) with RP with or without PT, a CO is recommended as the next step. If patients present at 4-6 months of age after prior attempts at RP and/or PT without improvement in head shape deformity, with measured deformity in the range described above, a $\mathrm{CO}$ is recommended. A typical patient presenting in the 4-6 month age range without an initial course of conservative management would be referred for RP/PT, with recommendation for cranial orthosis if there is no head shape improvement or if the deformity is worse at 4-6 week follow-up. We note clinically that combined deformities of occipital plagiocephaly and occipital brachycephaly have a more severe appearance even though the individual measurements may seem mild.

If patients initially present in the older age range (7-9 months), the time between conservative RP/PT management and prescription of $\mathrm{CO}$ therapy may be shortened as the velocity of head circumference growth slows. Depending on other factors, these patients are usually treated with a $\mathrm{CO}$ within a shorter timeframe following presentation to clinic. Because our experience has indicated limited benefit to orthotic therapy in infants presenting after 10 months of age, patients at that age of presentation are generally not treated with an orthosis unless special circumstances are present. ${ }^{15}$

In our program, $\mathrm{CO}$ therapy ends at 12 months of chronological age, adjusted for prematurity. Only 1 helmet is used, unless loss or damage occurs. The final 2D laser surface scanner measurements are taken at the time treatment is completed regardless of patient age.

\section{Statistical Analysis}

Multivariate logistic regression was applied to confirm the algorithm of recommended treatment. In addition, a multivariate regression model was used to estimate the effect of presenting patient characteristics and treatment modality on the outcomes of interest. Risk factors with $\mathrm{p}$ $<0.2$ in univariate analysis were included in multivariate analysis. All statistical analyses were performed with SAS (SAS Institute) and Stata 13.0 (StataCorp). A p value of $<0.05$ was considered statistically significant.

\section{Results}

For the period between 2007 and 2014, 1299 patients were screened in the Texas Children's Hospital Head Shape Clinic. Figure 2 delineates our study cohort with inclusion and exclusion criteria. Of those 1299 patients, 991 were less than 12 months of age at presentation and had char- 
acteristic positional deformities with no other exclusion criteria. These 991 patients are summarized in descriptive statistics in Tables 1-3. The distribution of patients' deformities included occipital plagiocephaly (69.5\%), occipital brachycephaly (18.4\%), and both (12.1\%), as defined above by laser surface measurement for this study. Of the 991 patients with recommended treatment plans, 884 returned for at least 1 follow-up appointment. A total of 552 patients were followed to completion of their recommended treatment and had a full set of records for analysis (Tables 4-5): they underwent final head shape measurement that could be compared with the initial studies.

The patients' average age at presentation was 6.2 months, and $69.3 \%$ were male. Obstetric history revealed $84.3 \%$ single gestation and $12.0 \%$ twin gestation or more, and $17.6 \%$ of mothers had a history or symptoms that strongly suggested intrauterine constraint. Of these, uterine constraint factors included breech presentation (3.4\%), uterine malformation (12.6\%), transverse position (0.6\%), and oligohydramnios $(0.9 \%)$. The patients' birth weight ranged from 1.1 to $11.3 \mathrm{lbs}$ (mean $7.8 \mathrm{lbs}$, SD $1.7 \mathrm{lbs}$ ), and $22.3 \%$ had a history of premature birth.

\section{Recommended Treatment}

Of the 991 patients in our cohort, 543 patients (54.8\%) were initially managed with RP or PT. These patients were, on average, 6.1 months of age (SD 2.1 months). The mean age of patients who were recommended for CO therapy at presentation was 6.4 months (SD 1.5 months). Patients who first had RP/PT without significant improvement and transitioned to $\mathrm{CO}$ therapy constituted a minority, totaling 137 patients (mean age 6.2 months, SD 1.7 months) (Table 2). Infants who presented with more severe deformity or at older age were more likely to be initially managed with a custom CO (Table 3 ).

\section{Outcomes in Head Shape Improvement}

Those patients recommended for RP/PT had less deformity at presentation and overall lower initial ODD than those recommended for $\mathrm{CO}$. Of those patients initially treated with RP/PT, those who ended up crossing over to $\mathrm{CO}$ therapy had more severe deformity at presentation (Tables 2 and 3). For instance, the mean ODD at presentation for positional plagiocephaly patients initially recommended for RP/PT was 10.3 (SD 3.8), while for CO it was 14.0 (SD 3.9) and for those who eventually received $\mathrm{CO}$ after RP/PT (RP/PT/CO) it was 14.7 (SD 3.7).

CO therapy was well tolerated; compliance with orthotic helmet use recommendations was reported in $95.2 \%$ of cases. Only a small number of patients experienced side effects or complications in CO therapy, such as skin irritation or rash, that required discontinuation of the treatment.

The absolute difference between the first ODD at presentation and the last ODD at conclusion of treatment (ODD change) was examined (Table 4). The absolute percentages of improvement in ODD were $36.7 \%, 33.5 \%$, and $15.1 \%$ for patients who treated with $\mathrm{CO}, \mathrm{RP} / \mathrm{PT} / \mathrm{CO}$, and $\mathrm{RP} / \mathrm{PT}$, respectively. Univariate analysis showed that sex, race, insurance, diagnosis, sleep position, torticollis history, and multiple gestation were not significantly associated with magnitude of ODD change during treatment.
The factors identified as significantly associated with magnitude of ODD change included corrected age at presentation and type of treatment received. The $\mathrm{CO}$ group had the largest ODD change $(5.8 \mathrm{~mm}$ difference in mean values, $36.7 \%$ ODD change) as compared with the RP/PT group $(1.7 \mathrm{~mm}, 15.1 \%)$ or the $\mathrm{RP} / \mathrm{PT} / \mathrm{CO}$ crossover group (4.8 mm, 33.5\%). Meanwhile, CO therapy also improved cephalic ratios in positional occipital brachycephaly. Patients receiving CO therapy improved an additional 0.266 in cephalic ratio (difference in mean values before and after treatment) as compared with patients receiving RP or PT. The difference between RP/PT and crossover RP/ PT/CO group in cephalic ratio was small but statistically significant $(0.036, \mathrm{p}<0.001)$ (Table 5).

\section{Discussion}

Our retrospective review of the treatment and outcomes of 991 patients with positional skull deformation showed the impact of age and of treatment modality on results.

Age at presentation and severity of deformity play an important role in selection of and response to initial treatment. Similar to previous studies, ${ }^{3,8,12}$ in this study infants presenting between 4 and 9 months were more likely to be recommended for $\mathrm{CO}$ therapy than those presenting younger or older than this age window (age $>4-6$ months, OR 4.227, p < 0.001; age >6-9 months, OR 4.209, p < 0.001 ) (Table 3). CO therapy was recommended for $71.7 \%$ of our patients in the 4- to 9-month age range, while it was only recommended for $16.6 \%$ of patients presenting under the age of 4 months and only $14.3 \%$ of patients presenting after 9 months. Patients presenting with a high severity of deformity as measured by different methods in the literature are more likely to undergo orthotic therapy. ${ }^{7,19}$ Our study is consistent with these reports as patients presenting with a large first ODD (OR 1.258, $\mathrm{p}<0.001)$ or high cephalic ratio (OR 1.007, $\mathrm{p}<0.001$ ) were more likely to undergo $\mathrm{CO}$ therapy.

In support of our treatment algorithm and emphasis on early referral to our head shape evaluation clinic, we show in Table 5 that earlier age at presentation was significantly associated with larger magnitude of improvement in measured outcomes (Table 5). Our findings agree with prior studies, which call for earlier referrals and $\mathrm{CO}$ intervention as a statistically significant marker of overall benefit. $3,5,8$ Total duration of helmet use has a weaker correlation with overall benefit, which implies that benefit is achieved during rapid growth phases rather than the overall duration of helmet use and underscores the importance of early referral. Our data corroborate these reports in that our patients beginning $\mathrm{CO}$ therapy prior to 9 months of age experienced a greater benefit than patients not receiving a custom CO until after 9 months of age $(\mathrm{p}<0.001)$. When comparing the ODD and cephalic ratio improvement among our patient population, the largest changes in results were achieved in cases in which CO therapy was used at some point during clinical management, compared with cases in which RP and PT were used alone. This observation supports the treatment algorithm employed during our study in that it favors the use of CO therapy when indicated and also introduces cranial orthoses at the op- 
TABLE 1. Patient characteristics by recommended treatment

\begin{tabular}{|c|c|c|c|c|c|c|c|c|c|}
\hline \multirow[b]{2}{*}{ Variables } & \multicolumn{2}{|c|}{ Total } & \multicolumn{2}{|c|}{$\mathrm{CO}$} & \multicolumn{2}{|c|}{$\mathrm{RP} / \mathrm{PT}$} & \multicolumn{2}{|c|}{$\mathrm{RP} / \mathrm{PT} / \mathrm{CO}$} & \multirow[b]{2}{*}{ p Value } \\
\hline & $\mathrm{N}$ & $\%$ & $\mathrm{~N}$ & $\%$ & $\mathrm{~N}$ & $\%$ & $\mathrm{~N}$ & $\%$ & \\
\hline Corrected age at presentation & & & & & & & & & $<0.001 \dagger$ \\
\hline $0-4$ mos & 193 & 19.5 & 32 & 16.6 & 136 & 70.5 & 25 & 13.0 & \\
\hline$>4-6$ mos & 428 & 43.2 & 162 & 37.9 & 201 & 47.0 & 65 & 15.2 & \\
\hline$>6-9$ mos & 328 & 33.1 & 111 & 33.8 & 170 & 51.8 & 47 & 14.3 & \\
\hline$>9$ mos & 42 & 4.2 & 6 & 14.3 & 36 & 85.7 & 0 & 0 & \\
\hline Sex & & & & & & & & & $0.004 \dagger$ \\
\hline Female & 304 & 30.7 & 76 & 25.0 & 186 & 61.2 & 42 & 13.8 & \\
\hline Male & 687 & 69.3 & 235 & 34.2 & 357 & 52.0 & 95 & 13.8 & \\
\hline Race & & & & & & & & & 0.557 \\
\hline White & 403 & 40.7 & 130 & 32.3 & 227 & 56.3 & 46 & 11.4 & \\
\hline Black & 41 & 4.1 & 14 & 34.2 & 21 & 51.2 & 6 & 14.6 & \\
\hline Hispanic & 323 & 32.6 & 103 & 31.9 & 166 & 51.4 & 54 & 16.7 & \\
\hline Asian/other & 67 & 6.8 & 15 & 22.4 & 40 & 59.7 & 12 & 17.9 & \\
\hline Unknown & 157 & 15.8 & 49 & 31.2 & 89 & 56.7 & 19 & 12.1 & \\
\hline Insurance & & & & & & & & & 0.200 \\
\hline Medicaid/CHIP & 384 & 38.8 & 124 & 32.3 & 195 & 50.8 & 65 & 16.9 & \\
\hline Commercial & 512 & 51.7 & 158 & 30.9 & 298 & 58.2 & 56 & 10.9 & \\
\hline Others & 81 & 8.2 & 21 & 25.9 & 44 & 54.3 & 16 & 19.8 & \\
\hline Unknown & 14 & 1.4 & 8 & 57.1 & 6 & 42.9 & 0 & 0 & \\
\hline Diagnosis & & & & & & & & & $<0.001 \uparrow$ \\
\hline Plagiocephaly & 689 & 69.5 & 186 & 27.0 & 381 & 55.3 & 122 & 17.7 & \\
\hline Brachycephaly & 182 & 18.4 & 69 & 37.9 & 104 & 57.1 & 9 & 5.0 & \\
\hline Both & 120 & 12.1 & 56 & 46.7 & 58 & 48.3 & 6 & 5.0 & \\
\hline Multiple gestation & & & & & & & & & $<0.001 \dagger$ \\
\hline Single birth & 835 & 84.3 & 240 & 28.7 & 476 & 57.0 & 119 & 14.3 & \\
\hline Multiple birth & 119 & 12.0 & 52 & 43.7 & 51 & 42.9 & 16 & 13.5 & \\
\hline Unknown & 37 & 3.7 & 19 & 51.4 & 16 & 43.2 & 2 & 5.4 & \\
\hline Torticollis & & & & & & & & & $0.010 \dagger$ \\
\hline Yes & 373 & 37.6 & 96 & 25.7 & 177 & 47.5 & 100 & 26.8 & \\
\hline No & 587 & 59.2 & 203 & 34.6 & 348 & 59.3 & 36 & 6.1 & \\
\hline Unknown & 31 & 3.1 & 12 & 38.7 & 18 & 58.1 & 1 & 3.2 & \\
\hline Sleep position & & & & & & & & & $<0.001 \uparrow$ \\
\hline Supine & 372 & 37.5 & 151 & 40.6 & 186 & 50.0 & 35 & 9.4 & \\
\hline Prone & 26 & 2.6 & 13 & 50.0 & 11 & 42.3 & 2 & 7.7 & \\
\hline Side & 568 & 57.3 & 135 & 23.8 & 333 & 58.6 & 100 & 17.6 & \\
\hline Unknown & 25 & 2.5 & 12 & 48.0 & 13 & 52.0 & 0 & 0.0 & \\
\hline Delivery type & & & & & & & & & $0.091 \dagger$ \\
\hline Vaginal & 513 & 51.8 & 157 & 30.6 & 276 & 53.8 & 80 & 15.6 & \\
\hline Vaginal w/ assistive device & 24 & 2.4 & 12 & 50.0 & 11 & 45.8 & 1 & 4.2 & \\
\hline C-section & 398 & 40.2 & 119 & 29.9 & 230 & 57.8 & 49 & 12.3 & \\
\hline Unknown & 56 & 5.7 & 23 & 41.1 & 26 & 46.4 & 7 & 12.5 & \\
\hline Premature & & & & & & & & & 0.823 \\
\hline Yes & 221 & 22.3 & 68 & 30.8 & 114 & 51.6 & 39 & 17.7 & \\
\hline No & 770 & 77.7 & 243 & 31.6 & 429 & 55.7 & 98 & 12.7 & \\
\hline
\end{tabular}

$\mathrm{CHIP}=$ Children's Health Insurance Program; $\mathrm{CO}=$ cranial orthosis; $\mathrm{C}$-section = cesarean section; $\mathrm{PT}=$ physical therapy; $\mathrm{RP}=$ repositioning.

* The $p$ value was the result of univariate analysis for 2 groups (HM vs RP/PT or RP/PT/HM) instead of 3-group comparison.

$\dagger$ Covariates with $p<0.2$ at univariate analysis were included in the multivariate logistic model. 
TABLE 2. Patient characteristics and measurements (continuous variables) by recommended treatment

\begin{tabular}{|c|c|c|c|c|}
\hline $\begin{array}{c}\text { Baseline Characteristic } \\
\text { \& Recommended } \\
\text { Treatment }\end{array}$ & $\mathrm{N}$ & Mean (SD) & Range & $\begin{array}{c}p \\
\text { Value }\end{array}$ \\
\hline \multicolumn{5}{|l|}{ Weight in Ibs } \\
\hline All & 860 & $7.8(1.7)$ & $1.1-11.3$ & 0.06 \\
\hline $\mathrm{CO}$ & 275 & $7.9(1.6)$ & $1.4-11.3$ & \\
\hline $\mathrm{RP} / \mathrm{PT}$ & 465 & $7.8(1.6)$ & $1.1-11.1$ & \\
\hline RP/PT/CO & 120 & $7.5(1.9)$ & $1.3-11.3$ & \\
\hline \multicolumn{5}{|l|}{ Corrected age in mos* } \\
\hline All & 991 & $5.8(1.9)$ & $0.7-11$ & 0.299 \\
\hline $\mathrm{CO}$ & 311 & $5.9(1.5)$ & $1.3-11$ & \\
\hline RP/PT & 543 & $5.7(2.2)$ & $0.7-11$ & \\
\hline $\mathrm{RP} / \mathrm{PT} / \mathrm{CO}$ & 137 & $5.6(1.6)$ & $1.3-9$ & \\
\hline \multicolumn{5}{|l|}{$\begin{array}{l}\text { Chronological age in } \\
\text { mos }^{*}\end{array}$} \\
\hline All & 991 & $6.2(1.8)$ & $1-11$ & 0.198 \\
\hline $\mathrm{CO}$ & 311 & $6.4(1.5)$ & $2-11$ & \\
\hline RP/PT & 543 & $6.1(2.1)$ & $1-11$ & \\
\hline RP/PT/CO & 137 & $6.2(1.7)$ & $2-11$ & \\
\hline \multicolumn{5}{|l|}{ ODD } \\
\hline All $\dagger$ & 742 & $12.1(4.3)$ & $0.1-37.9$ & $<0.001$ \\
\hline $\mathrm{CO}$ & 223 & $14.0(3.9)$ & $4-27$ & \\
\hline RP/PT & 404 & $10.3(3.8)$ & $0.1-37.9$ & \\
\hline $\mathrm{RP} / \mathrm{PT} / \mathrm{CO}$ & 115 & $14.7(3.7)$ & $2.7-22.9$ & \\
\hline \multicolumn{5}{|l|}{$\mathrm{CR}$} \\
\hline All & 281 & $0.972(0.045)$ & $0.808-1.102$ & $<0.001$ \\
\hline $\mathrm{CO}$ & 122 & $0.982(0.048)$ & $0.808-1.096$ & \\
\hline RP/PT & 147 & $0.963(0.040)$ & $0.866-1.102$ & \\
\hline $\mathrm{RP} / \mathrm{PT} / \mathrm{CO}$ & 12 & $1.003(0.035)$ & $0.934-1.052$ & \\
\hline $\begin{array}{l}\text { CR = cephalic ratio. } \\
\text { * At presentation. } \\
\dagger \text { Plagiocephaly only a } \\
\ddagger \text { Brachycephaly only }\end{array}$ & . & $\begin{array}{l}\text { loses. } \\
\text { noses. }\end{array}$ & & \\
\hline
\end{tabular}

timal time frame to take advantage of the period of rapid head growth to maximize therapeutic benefit.

When comparing the factors that ultimately influenced head shape improvement, multivariate regression favored $\mathrm{CO}$ therapy versus RP/PT with respect to magnitude of ODD change. Similarly, infants who initially started with $\mathrm{RP} / \mathrm{PT}$ and then crossed over to $\mathrm{CO}$ treatment achieved more improvement in ODD than those treated only with $\mathrm{RP} / \mathrm{PT}$.

Other reports have been published detailing the efficacy of $\mathrm{CO}$ in the correction of deformational plagiocephaly and brachycephaly, yet there is no definitive body of evidence to support the use of CO therapy as the gold standard. ${ }^{2,7,13,14,18}$ Despite support for the use of cranial orthoses, some studies have compared outcomes of customized $\mathrm{CO}$ use versus RP and found minimal differences between cohorts treated with these approaches. ${ }^{3,10,11,19}$ Conclusions drawn from these studies also commonly determine that financial burden and lack of proven therapeutic benefit
TABLE 3. Determinants of initial recommended treatment: CO versus RT/PT or RP/PT/CO

\begin{tabular}{|c|c|c|c|}
\hline Determinant & OR & $95 \% \mathrm{Cl}$ & $p$ Value \\
\hline First ODD & 1.258 & $1.196-1.323$ & $<0.001^{*}$ \\
\hline First CR × 1000 & 1.007 & $1.004-1.011$ & $<0.001^{*}$ \\
\hline \multicolumn{4}{|l|}{ Corrected age at presentation } \\
\hline $0-4$ mos & $\operatorname{Ref}=1$ & & \\
\hline$>4-6$ mos & 4.277 & $2.559-7.147$ & $<0.001^{*}$ \\
\hline$>6-9 \mathrm{mos}$ & 4.209 & $2.436-7.271$ & $<0.001^{*}$ \\
\hline$>9 \mathrm{mos}$ & 1.521 & $0.508-4.555$ & 0.454 \\
\hline \multicolumn{4}{|l|}{ Sex } \\
\hline Female & $\operatorname{Ref}=1$ & & \\
\hline Male & 1.199 & $0.832-1.726$ & 0.330 \\
\hline \multicolumn{4}{|l|}{ Diagnosis } \\
\hline Brachycephaly & $\operatorname{Ref}=1$ & & \\
\hline Plagiocephaly & 0.539 & $0.394-0.986$ & $0.045^{*}$ \\
\hline Both & 0.287 & $0.150-0.547$ & $<0.001^{*}$ \\
\hline \multicolumn{4}{|l|}{ Multiple gestation } \\
\hline Single birth & $\operatorname{Ref}=1$ & & \\
\hline Multiple birth & 1.820 & $1.108-2.990$ & $0.018^{*}$ \\
\hline Unknown & 3.040 & $1.190-7.773$ & 0.020 \\
\hline \multicolumn{4}{|l|}{ Torticollis } \\
\hline Yes & $\operatorname{Ref}=1$ & & \\
\hline No & 1.454 & $0.997-2.120$ & 0.052 \\
\hline Unknown & 0.877 & $0.286-2.688$ & 0.818 \\
\hline \multicolumn{4}{|l|}{ Sleep position } \\
\hline Supine & $\operatorname{Ref}=1$ & & \\
\hline Prone & 1.701 & $0.688-4.203$ & 0.250 \\
\hline Side & 0.444 & $0.302-0.653$ & $<0.001^{*}$ \\
\hline Unknown & 0.668 & $0.203-2.024$ & 0.508 \\
\hline \multicolumn{4}{|l|}{ Delivery type } \\
\hline Vaginal & $\operatorname{Ref}=1$ & & \\
\hline Vaginal w/ assistive device & 2.973 & $1.001-8.827$ & 0.050 \\
\hline C-section & 2.975 & $0.682-1.394$ & 0.888 \\
\hline Unknown & 2.007 & $0.957-4.210$ & 0.065 \\
\hline
\end{tabular}

Ref = reference.

* Interpretation: $\mathrm{OR}<1$, less likely to be treated with cranial orthosis; $\mathrm{OR}>1$, more likely to be treated initially with cranial orthosis.

dissuade practitioners from recommending orthotic treatment. For instance, van Wijk et al. ${ }^{18}$ published a randomized controlled trial of helmet therapy versus conservative management with the objective of assessing the efficacy of treatment in 84 Dutch infants with positional skull deformation aged 5-6 months. The authors concluded that there was no quantifiable difference in outcomes between helmet therapy and natural history with conservative management. Full correction of head shape asymmetry was achieved in only $26 \%$ of the helmet therapy cohort and $23 \%$ of the natural course cohort (OR 1.2). This study incorporated restrictive inclusion criteria of age 5-6 months, at least 36 weeks' gestation, and no history of muscular torticollis, craniosynostosis, or dysmorphic features. In- 
TABLE 4. Head shape measurements before/after treatment course

\begin{tabular}{|c|c|c|c|c|c|c|c|c|c|}
\hline \multirow{3}{*}{$\begin{array}{l}\text { Diagnosis } \\
\text { \& Treatment }\end{array}$} & \multirow{3}{*}{$\begin{array}{c}\text { No. } \\
\text { of } \\
\text { Cases }\end{array}$} & \multicolumn{4}{|c|}{ ODD } & \multicolumn{4}{|c|}{$\mathrm{CR}$} \\
\hline & & \multicolumn{2}{|c|}{ Mean in mm (SD) } & \multirow{2}{*}{$\begin{array}{l}\text { Improvement } \\
(\mathrm{mm})\end{array}$} & \multirow{2}{*}{$\begin{array}{c}\% \\
\text { Improvement }\end{array}$} & \multicolumn{2}{|c|}{ Mean (SD) } & \multirow[b]{2}{*}{ Improvement } & \multirow{2}{*}{$\begin{array}{c}\% \\
\text { Improvement }\end{array}$} \\
\hline & & First & Last & & & First & Last & & \\
\hline Plagiocephaly & 379 & & & & & & & & \\
\hline $\mathrm{CO}$ & 122 & $15.3(3.4)$ & $9.5(2.9)$ & 5.8 & 36.7 & - & - & - & - \\
\hline $\mathrm{RP} / \mathrm{PT} / \mathrm{CO}$ & 120 & $13.9(3.5)$ & $9.1(3.2)$ & 4.8 & 33.5 & - & - & - & - \\
\hline RP/PT & 137 & $10.9(3.2)$ & $9.2(3.4)$ & 1.7 & 15.1 & - & - & - & - \\
\hline Brachycephaly & 87 & & & & & & & & \\
\hline $\mathrm{CO}$ & 50 & - & - & - & - & $0.975(0.062)$ & $0.930(0.054)$ & 0.045 & 4.6 \\
\hline $\mathrm{RP} / \mathrm{PT} / \mathrm{CO}$ & 9 & - & - & - & - & $1.000(0.054)$ & $0.942(0.041)$ & 0.058 & 5.7 \\
\hline RP/PT & 28 & - & - & - & - & $0.973(0.041)$ & $0.955(0.034)$ & 0.019 & 1.9 \\
\hline Dual diagnosis* & 86 & & & & & & & & \\
\hline $\mathrm{CO}$ & 41 & $11.9(4.1)$ & $7.3(3.0)$ & 4.5 & 37.0 & $0.977(0.035)$ & $0.932(0.038)$ & 0.044 & 4.5 \\
\hline RP/PT/CO & 21 & $10.0(3.6)$ & $6.3(3.0)$ & 3.8 & 35.9 & $0.973(0.031)$ & $0.918(0.031)$ & 0.055 & 5.6 \\
\hline RP/PT & 24 & $9.5(2.9)$ & $7.9(2.6)$ & 1.6 & 15.6 & $0.957(0.030)$ & $0.938(0.030)$ & 0.019 & 2.0 \\
\hline
\end{tabular}

* Both occipital plagiocephaly and occipital brachycephaly.

fants categorized as having severe deformity were excluded from the study. The authors used a cutoff of an ODD index of $113 \%$, a calculated ratio based on external caliper measurement. Notably, the external caliper method used for measurement in this study is difficult to standardize, as it is operator dependent and subject to measurement error. Importantly, the study did not use customized CO helmets; instead, the study participants used generic "off-the-shelf" protective helmets without dedicated follow-up of management by experienced orthotists.

Steinberg et al. ${ }^{17}$ reported on a large experience with 4378 patients with deformational plagiocephaly and brachycephaly. They demonstrated that conservative therapy (RP/PT) is equally effective as use of a customized CO in correcting head shape. The study followed 2847 infants treated conservatively with involvement of specialized physical therapists and 1531 treated with a custom $\mathrm{CO}$ (including 521 patients who crossed over from RP/ $\mathrm{PT})$. The patients were observed for as long as 18 months or until correction, defined as an ODD less than $5 \mathrm{~mm}$ for plagiocephaly and cephalic ratio less than 0.85 for brachycephaly. Head shape measurements were based on objective laser surface scans performed by an experienced orthotics team. Patient age at enrollment was within the range classically shown to benefit from $\mathrm{CO}$ therapy (mean age for RP/PT 5.1 months [SD 2.1 months]; for CO therapy, 7.1 months [SD 3.8 months]). This study not only found RP and PT to be effective (correction in $91.6 \%$ of patients treated with RP/PT alone and $95 \%$ of patients treated with a helmet), but also demonstrated that a trial of RP/PT can be used as an initial measure for patients before the initiation of treatment with $\mathrm{CO}$ with good results $(\mathrm{ODD}<5$ $\mathrm{mm})$. The authors thus concluded that CO therapy could be delayed to an older age if the patient is first treated with $\mathrm{RP} / \mathrm{PT}$. Unlike the authors of the small randomized study from the Netherlands, Steinberg et al. were able to document excellent head shape correction in a vast majority of patients.
Our experience echoes previous reports of improvement in deformational positional plagiocephaly in infants. Patients undergoing RP, PT, and CO therapy all had measured improvement. Patients who crossed over from $\mathrm{RP} / \mathrm{PT}$ to $\mathrm{CO}$ also experienced correction of head shape. Our age range differed from that of the large study mentioned above: patients in our practice were followed until 12 months of age instead of 18 months. In addition, the goal for end of treatment was ODD $<10 \mathrm{~mm}$ instead of ODD $<5 \mathrm{~mm}$. Our treatment rationale is that correction or elimination of the underlying deformational forces allows for progression toward continuing improvement. Our experience showed a greater magnitude of improvement

TABLE 5. Factors associated with head shape improvement

\begin{tabular}{|c|c|c|c|}
\hline Measurement \& Factor & $\begin{array}{l}\text { Coefficient } \\
(\text { Ref }=0)\end{array}$ & $95 \% \mathrm{Cl}$ & $\begin{array}{c}p \\
\text { Value }\end{array}$ \\
\hline \multicolumn{4}{|l|}{ Measurement: ODD $(n=465)$} \\
\hline \multicolumn{4}{|l|}{ Received treatment } \\
\hline RP/PT vs CO & 4.235 & $3.602-4.868$ & $<0.001$ \\
\hline RP/PT vs RP/PT/CO & 3.158 & $2.539-3.778$ & $<0.001$ \\
\hline \multicolumn{4}{|l|}{$\begin{array}{l}\text { Corrected age at presenta- } \\
\text { tion }\end{array}$} \\
\hline $0-4$ vs $>4-6$ mos & -1.791 & -2.386 to -1.196 & $<0.001$ \\
\hline $0-4$ vs $>6-11 \mathrm{mos}$ & -2.642 & -3.362 to -1.922 & $<0.001$ \\
\hline \multicolumn{4}{|l|}{ Measurement: CR $(n=173)$} \\
\hline \multicolumn{4}{|l|}{ Received treatment } \\
\hline RP/PT vs CO & 0.266 & $0.019-0.034$ & $<0.001$ \\
\hline RP/PT vs RP/PT/CO & 0.036 & $0.026-0.046$ & $<0.001$ \\
\hline \multicolumn{4}{|l|}{$\begin{array}{l}\text { Corrected age at presenta- } \\
\text { tion }\end{array}$} \\
\hline $0-4$ vs $>4-6$ mos & 0.006 & -0.003 to 0.014 & 0.209 \\
\hline $0-4$ vs $>6-11 \mathrm{mos}$ & -0.006 & -0.016 to 0.004 & 0.230 \\
\hline
\end{tabular}


in the group receiving $\mathrm{CO}$ therapy than in those receiving $\mathrm{RP} / \mathrm{PT}$. This effect was observed whether patients crossed over to CO or started with CO. However, it is important to note that our study was retrospective (without controls), describing measured outcomes in a patient population treated under a specific pathway and rationale as described above. Patients were not randomized in this study, and we did not attempt to compare RP/PT to CO. In the treatment algorithm applied over 7 years, $\mathrm{CO}$ is a "built-in" treatment option in the setting of lack of improvement in head shape with RP/PT over time.

\section{Strengths and Limitations}

Each patient was seen and counseled by a pediatric neurosurgeon on the head shape screening team. In addition to clinical evaluation and judgment about the degree of deformity, we used the surface laser STAR scanner to track objective measurements. These measurements at Level 3 of the scan may sometimes underestimate the deformity seen on clinical examination and thus do not substitute for clinical examination. While the potential limitations of 2D surface scans are recognized, the results do offer the advantage of providing an objective platform for measurement and comparison of results by an individual and with the literature.

The follow-up period for our patients ends at the end of treatment. It is possible that improvement may continue after that time. One would surmise that such improvement would continue in all groups at a similar rate; therefore, the conclusions reached would still be valid in that there would be the same relationship among treatment groups. This reasoning is speculative, however, and future studies with long-term follow up are needed.

This was a retrospective study relying on chart review, and the clinical data are incomplete. Patients were not randomized to treatment; therefore, patient-specific factors and parental preferences may have influenced the treatment decisions. The study was observational in nature and reflects the treatment algorithm developed in our practice. There was no comparison group in this retrospective study. Follow-up was not mandatory for conservatively managed patients with mild deformity, which may have increased the incomplete follow-up in our study. This differential follow-up pattern may be a source of confounding bias. In addition, patients were released from treatment at 12 months of age, so any further improvements in head shape were not measured or captured. While we report that only a small number of patients experienced any complications of $\mathrm{CO}$ use such as skin breakdown, we were not able to measure other disadvantages and considerations of CO therapy. The cost of the orthosis itself and related costs, in terms of the families' time and resources for fitting encounters and clinic visits, were not measured in this retrospective study. In addition, the larger philosophical question of the need for treatment of positional plagiocephaly and cranial abnormalities is beyond the scope of this study.

Encouragement to initiate treatment of head shape abnormalities with RP/PT is standard in general pediatric practice. ${ }^{9}$ Treatment algorithms specifying the duration of and use of conservative therapy versus cranial orthotic therapy vary in the literature. Our 7-year study offers an algorithm that categorizes treatment based on age at presentation $(0-4,>4-6,>6-9$, and $>9$ months) and severity of cranial deformity, informed by the anticipated natural history of cranial growth.

\section{Conclusions}

In a 7-year retrospective review of 991 patients evaluated for positional head shape deformity, younger age at presentation for evaluation in our multidisciplinary head shape clinic and use of $\mathrm{CO}$ treatment were most predictive of better correction of positional skull deformity.

\section{References}

1. Argenta L, David L, Thompson J: Clinical classification of positional plagiocephaly. J Craniofac Surg 15:368-372, 2004

2. Clarren SK: Plagiocephaly and torticollis: etiology, natural history, and helmet treatment. J Pediatr 98:92-95, 1981

3. Graham JM Jr, Gomez M, Halberg A, Earl DL, Kreutzman JT, Cui J, et al: Management of deformational plagiocephaly: repositioning versus orthotic therapy. J Pediatr 146:258262, 2005

4. Hutchison BL, Stewart AW, Mitchell EA: Characteristics, head shape measurements and developmental delay in 287 consecutive infants attending a plagiocephaly clinic. Acta Paediatr 98:1494-1499, 2009

5. Kelly KM, Littlefield TR, Pomatto JK, Ripley CE, Beals SP, Joganic EF: Importance of early recognition and treatment of deformational plagiocephaly with orthotic cranioplasty. Cleft Palate Craniofac J 36:127-130, 1999

6. Kennedy E, Majnemer A, Farmer JP, Barr RG, Platt RW: Motor development of infants with positional plagiocephaly. Phys Occup Ther Pediatr 29:222-235, 2009

7. Kluba S, Kraut W, Calgeer B, Reinert S, Krimmel M: Treatment of positional plagiocephaly-helmet or no helmet? J Craniomaxillofac Surg 42:683-688, 2014

8. Kluba S, Kraut W, Reinert S, Krimmel M: What is the optimal time to start helmet therapy in positional plagiocephaly? Plast Reconstr Surg 128:492-498, 2011

9. Laughlin J, Luerssen TG, Dias MS: Prevention and management of positional skull deformities in infants. Pediatrics 128:1236-1241, 2011

10. Lipira AB, Gordon S, Darvann TA, Hermann NV, Van Pelt AE, Naidoo SD, et al: Helmet versus active repositioning for plagiocephaly: a three-dimensional analysis. Pediatrics 126:e936-e945, 2010

11. Loveday BP, de Chalain TB: Active counterpositioning or orthotic device to treat positional plagiocephaly? J Craniofac Surg 12:308-313, 2001

12. Mortenson P, Steinbok P, Smith D: Deformational plagiocephaly and orthotic treatment: indications and limitations. Childs Nerv Syst 28:1407-1412, 2012

13. Mulliken JB, Vander Woude DL, Hansen M, LaBrie RA, Scott RM: Analysis of posterior plagiocephaly: deformational versus synostotic. Plast Reconstr Surg 103:371-380, 1999

14. Schweitzer T, Böhm H, Linz C, Jager B, Gerstl L, Kunz F, et al: Three-dimensional analysis of positional plagiocephaly before and after molding helmet therapy in comparison to normal head growth. Childs Nerv Syst 29:1155-1161, 2013

15. Shweikeh F, Nuño M, Danielpour M, Krieger MD, Drazin D: Positional plagiocephaly: an analysis of the literature on the effectiveness of current guidelines. Neurosurg Focus 35(4): E1, 2013

16. Speltz ML, Collett BR, Stott-Miller M, Starr JR, Heike C, Wolfram-Aduan AM, et al: Case-control study of 
neurodevelopment in deformational plagiocephaly.

Pediatrics 125: e537-e542, 2010

17. Steinberg JP, Rawlani R, Humphries LS, Rawlani V, Vicari FA: Effectiveness of conservative therapy and helmet therapy for positional cranial deformation. Plast Reconstr Surg 135:833-842, 2015

18. van Wijk RM, van Vlimmeren LA, Groothuis-Oudshoorn CG, Van der Ploeg CP, IJzerman MJ, Boere-Boonekamp MM: Helmet therapy in infants with positional skull deformation: randomised controlled trial. BMJ 348:g2741, 2014

19. Vles JS, Colla C, Weber JW, Beuls E, Wilmink J, Kingma $\mathrm{H}$ : Helmet versus nonhelmet treatment in nonsynostotic positional posterior plagiocephaly. J Craniofac Surg 11:572-574, 2000

\section{Disclosures}

The authors report no conflicts of interest concerning the materi- als or methods used in this study or the findings specified in this paper.

\section{Author Contributions}

Conception and design: Lam, Pan, Luerssen. Acquisition of data: Strickland, Hadley, Daniels, Brookshier, Luerssen. Drafting the article: Lam, Pan, Strickland. Critically revising the article: all authors. Reviewed submitted version of manuscript: all authors. Administrative/technical/material support: Luerssen. Study supervision: Lam, Pan, Luerssen.

\section{Correspondence}

Sandi Lam, Department of Neurosurgery, Baylor College of Medicine, Texas Children's Hospital, 6701 Fannin St., Ste. 1230, Houston, TX 77030. email: sklam@texaschildrens.org. 